\title{
Determination of minimum inhibitory concentration of Azithromycin, Ofloxacin and Ceftriaxone in Ciprofloxacin resistant Salmonella causing enteric fever
}

\author{
Shamima Kawser ${ }^{1}$, Md. Ruhul Amin Miah², Ahmed Abu Saleh², Khandker Md. Nurus Sabah³, Tanzima Begum ${ }^{4}$ \\ ${ }^{1}$ Department of Microbiology, Delta Medical College, Mirpur-1, Dhaka, ${ }^{2}$ Department of Microbiology \& Immunology, BSMMU, \\ Shahbag, Dhaka, ${ }^{3}$ Department of Cardiology, Dhaka Medical College, Dhaka, ${ }^{4}$ Department of Pharmacology \& Therapeutics, \\ Delta Medical College, Mirpur-1, Dhaka
}

\begin{abstract}
The therapeutic alternatives available for use against ciprofloxacin resistant enteric fever isolates in an endemic area are limited. The antibiotics currently available are the quinolones, third-generation cephalosporins and azithromycin. In this study, the MICs of various drugs were determined for 100 enteric fever isolates (72 Salmonella enterica serovar typhi and 28 Salmonella enterica serovar paratyphi A ). Ciprofloxacin resistant $(100 \%)$ Salmonella strains were sensitive to ofloxacin and ceftriaxone showing MICs of $0.0078-2 \mathrm{~g} / \mathrm{ml}$ and $0.0156-2 \mathrm{~g} / \mathrm{ml}$ respectively. Salmonella strains (98\%) had MIC values $1-32 \mathrm{~g} / \mathrm{ml}$ for azithromycin. These results indicate that ofloxacin and ceftriaxone may be convenient alternative antimicrobial agents for Salmonella isolates.
\end{abstract}

Keywords: Salmonella, Minimum inhibitory concentration, Multi drug resistant Salmonella

\section{Introduction}

Enteric fever is caused by Salmonella typhi \& Salmonella paratyphi A.B.C. Infection caused by ingestion of organisms in contaminated food or water or from contaminated hand 1 . From 1948 to 1970s chloramphenicol was the drug of choice in developed countries and its use resulted in a reduction in mortality rates from $10 \%$ to $2 \%{ }^{2}$. Chloramphenicol resistant Salmonella strains first reported in Britain, in 1950 and in India in 1972. Gradually, resistance to multiple antibiotics developed. The first major epidemic of multidrug-resistant (MDR) Salmonella typhi (isolates resistant to ampicillin, chloramphenicol and cotrimoxazole) was reported in 1972 in Mexico ${ }^{3}$. In the last two decades, the worldwide emergence of multi-drug resistant strains of Salmonella has led to virtual withdrawal of chloramphenicol \& its replacement with fluoroquinolones and third generation cephalosporins. Clinical treatment failures after the administration of ciprofloxacin and other fluoroquinolones to patient with typhoid fever attributable to these strains have been reported ${ }^{4}$.

\section{Correspondence:}

Dr. Shamima Kawser

Assistant Professor

Department of Microbiology

Delta Medical College, Mirpur-1, Dhaka,
Where fluoroquinolones, such as ciprofloxacin and ofloxacin, have become widely used, isolates of Salmonella typhi and paratyphi with reduced susceptibility to fluoroquinolones have become common ${ }^{5}$. The prevalence of resistance of Salmonella typhi to ciprofloxacin is very high also in Bangladesh . The injudicious administration and rampant use of quinolones in Bangladesh probably contributed to the high prevalence of reduced susceptibility $(>88 \%)$ and the emergence of very high level or complete resistance $(>4$ $\mathrm{g} / \mathrm{ml}$ ) of isolates of Salmonella typhi to ciprofloxacin ${ }^{6}$. Furthermore, the recent report of an isolate of Salmonella typhi from Bangladesh with high level resistance to ceftriaxone means that, untreatable typhoid may become a reality. There is a need for alternative antimicrobial agents to treat such MDR infections ${ }^{7}$. In the present study, minimum inhibitory concentration of ciprofloxacin, ofloxacin, ceftriaxone and Azithromycin for Salmonella enterica serovar typhi was determined by agar dilution method.

The present study was aimed to compare the MICs of Azithromycin, Ofloxacin Ceftriaxone and Ciprofloxacin to find out the therapeutic alternative available for the treatment of enteric fever. 


\section{Methodology}

This cross-sectional study was carried out in the department of Microbiology \& Immunology, Bangabandhu Sheikh Mujib Medical University (BSMMU), Dhaka, during the period from January 2008 to December 2008.

One hundred Salmonella species were collected from Microbiology \& Immunology Laboratory of BSMMU. The isolated strains were identified by biochemical tests and preserved in nutrient agar slant at 2 to 8 degree Celsius.

Sensitivity of the isolates to the antimicrobial agents was done by agar dilution method in Mueller-Hinton agar media to determine the minimum inhibitory concentrations (MICs). The antimicrobial agents used were obtained from dry powder of known potencies.

Preparation of Antimicrobial Solutions: Powder of the antimicrobial agents were dissolved into appropriate solvents, as per instruction of the manufacturer. Stock solutions were prepared and sterilized by membrane filtration. Antimicrobial agents were diluted from stock solutions in distilled water to make a series of two-fold dilutions of intermediate concentrations, that were 10 times higher than the required final concentration in the agar medium.

Preparation of stock solution: For preparation of stock solution of antimicrobial agent $2000 \mathrm{ug}$ powder of antimicrobial agent was added to the per $\mathrm{ml}$ of distilled water (Lalitha, 2007

Preparation of the agar dilution plates: Mueller-Hinton agar base after dissolving into distilled water was autoclaved at $121^{\circ} \mathrm{C}$ for 15 minutes. After cooling to $50^{\circ} \mathrm{C}$ in a water bath antimicrobial solution was added. For preparing 5 petridish (90 $\mathrm{mm}$ diameter) $90 \mathrm{ml} \mathrm{media} \mathrm{and} 10 \mathrm{ml}$ antimicrobial solution was taken in a flask. Then the antibiotic containing medium was plated quickly ( $20 \mathrm{ml}$ for each petridish). After solidification, the plates were stored in sealed plastic bags at $4-8^{0} \mathrm{C}$.

Preparation of the Inocula: A bacterial suspension was made in sterile nutrient broth by colonies from a pure culture and the turbidity adjusted to $0.5 \mathrm{Mc}$ Farland standard to make a concentration of about $10^{7} \mathrm{CFU} / \mathrm{ml}$.

Inoculation: Using sterile microtips, $1 \mu \mathrm{l}$ of the diluted suspension containing $10^{4} \mathrm{CFU}$ was inoculated on to the appropriate MIC plates.

Incubation: The inoculated plates were incubated at $37^{\circ} \mathrm{C}$ for 18-24 hours.

\section{Rusults}

A total of 100 Salmonella strains were studied, of which 72(72.0\%) were Salmonella typhi, 28(28.0\%) were S. Paratyphi A and none was S. Paratyphi B. Table I shows the MIC value of ciprofloxacin among 100 Salmonella strains. Highest number of strains $36(36.0 \%)$ had MIC $2 \mu \mathrm{g} / \mathrm{ml}$ followed by $31(31.0 \%)$ strains with MIC $4 \mu \mathrm{g} / \mathrm{ml}, 11(11.0 \%)$ with MIC $0.05 \mu \mathrm{g} / \mathrm{ml}$, and $9(9 \%)$ with MIC $1 \mu \mathrm{g} / \mathrm{ml}$.

Table-I: MIC value of ciprofloxacin among the Salmonella strains $(n=100)$

\begin{tabular}{lcc}
\hline Sl & MIC value $(\mu \mathrm{g} / \mathrm{ml})$ & No. of strain \\
\hline 1 & 0.0625 & $0(0.0 \%)$ \\
2 & 0.125 & $0(0.0 \%)$ \\
3 & 0.25 & $4(4.0 \%)$ \\
4 & 0.5 & $11(11.0 \%)$ \\
5 & 1 & $9(9.0 \%)$ \\
6 & 2 & $36(36.0 \%)$ \\
7 & 4 & $31(31.0 \%)$ \\
8 & 8 & $9(9.0 \%)$ \\
9 & 16 & $0(0.0 \%)$ \\
& Total & $100(100 \%)$ \\
\hline
\end{tabular}

Table II shows the MIC value of ofloxacin among 100 Salmonella strains, Highest number of strains $23(23.0 \%)$ had MIC $0.125 \mu \mathrm{g} / \mathrm{ml}$ followed by $16(16 \%)$ strains with MIC $0.25 \mu \mathrm{g} / \mathrm{ml}, 14(14.0 \%)$ with MIC $0.5 \mu \mathrm{g} / \mathrm{ml}, 10(10.0 \%)$ with MIC $0.0625 \mu \mathrm{g} / \mathrm{ml}, 10(10.0 \%)$ with MIC $0.03125 \mu \mathrm{g} / \mathrm{ml}$, $8(8.0 \%)$ with MIC $0.0156 \mu \mathrm{g} / \mathrm{ml}$ and $8(8 \%)$ strains with MIC $0.0078 \mu \mathrm{g} / \mathrm{ml}$ and $7(7.0 \%)$ with MIC $2 \mu \mathrm{g} / \mathrm{ml}$ regarding MIC breakpoint in terms of sensitivity $100 \%$ strains were sensitive

Table-II: MIC value of ofloxacin among the Salmonella strains $(n=100)$

\begin{tabular}{lcc}
\hline SI & MIC value $(\boldsymbol{\mu g} / \mathbf{m l})$ & No. of isolates \\
\hline 1 & 0.004 & $0(0.0 \%)$ \\
2 & 0.0078 & $8(8.0 \%)$ \\
3 & 0.0156 & $8(8.0 \%)$ \\
4 & 0.03125 & $10(10.0 \%)$ \\
5 & 0.0625 & $10(10.0 \%)$ \\
6 & 0.125 & $23(23.0 \%)$ \\
7 & 0.25 & $16(16.0 \%)$ \\
8 & 0.5 & $14(14.0 \%)$ \\
9 & 1 & $7(7.0 \%)$ \\
10 & 2 & $4(4.0 \%)$ \\
11 & 4 & $0(0.0 \%)$ \\
12 & 8 & $0(0.0 \%)$ \\
& Total & $100(100 \%)$. \\
\hline
\end{tabular}


Table III shows the MIC value of ceftriaxone among 100 Salmonella strains. Highest number of strains $38(38.0 \%)$ had MIC $0.125 \mu \mathrm{g} / \mathrm{ml}$, followed by $28(28.0 \%)$ strains with MIC $0.0625 \mu \mathrm{g} / \mathrm{ml}, 20(20.0 \%)$ strains with MIC $0.03125 \mu \mathrm{g} / \mathrm{ml}$, $7(7.0 \%)$ strains with MIC $0.25 \mu \mathrm{g} / \mathrm{ml}$. Regarding MIC breakpoint in terms of sensitivity $100 \%$ strains were sensitive to ceftriaxone .

Table- III: MIC value of ceftriaxone among the Salmonella strains $(\mathrm{n}=100)$

\begin{tabular}{lcc}
\hline Sl & MIC value $(\boldsymbol{\mu g} / \mathbf{m l})$ & No. of isolates \\
\hline 1 & 0.004 & $0(0.0 \%)$ \\
2 & 0.0078 & $0(0.0 \%)$ \\
3 & 0.0156 & $4(4.0 \%)$ \\
4 & 0.03125 & $20(20.0 \%)$ \\
5 & 0.0625 & $28(28.0 \%)$ \\
6 & 0.125 & $38(38.0 \%)$ \\
7 & 0.25 & $7(7.0 \%)$ \\
8 & 0.5 & $0(0.0 \%)$ \\
9 & 1 & $2(2.0 \%)$ \\
10 & 2 & $1(1.0 \%)$ \\
11 & 4 & $0(0.0 \%)$ \\
& Total & $100(100 \%)$ \\
\hline
\end{tabular}

Table IV shows MIC value of Azithromycin among 100 Salmonella strains. Highest numbers of strains $36(36.0 \%)$ had MIC $8 \mu \mathrm{g} / \mathrm{ml}$, followed by $28(28.0 \%)$ strains with MIC 4 $\mu \mathrm{g} / \mathrm{ml}, 19(19.0 \%)$ strains with MIC $2 \mu \mathrm{g} / \mathrm{ml}, 9(9.0 \%)$ strains with MIC $16 \mu \mathrm{g} / \mathrm{ml}, 2$ strains with MIC $32 \mu \mathrm{g} / \mathrm{ml}$ and 2 strains with MIC $64 \mu \mathrm{g} / \mathrm{ml}$. Azithromycin has no definitive breakpoints for Salmonella isolates so either resistant or sensitive figure had not been given.

Table-IV: MIC value of azithromycin among the Salmonella strains $(\mathrm{n}=100)$

\begin{tabular}{lcc}
\hline Sl & MIC value $(\boldsymbol{\mu g} / \mathbf{m l})$ & No. of isolates \\
\hline 1 & 0.0625 & $0(0.0 \%)$ \\
2 & 0.125 & $0(0.0 \%)$ \\
3 & 0.25 & $0(0.0 \%)$ \\
4 & 0.5 & $0(0.0 \%)$ \\
5 & 1 & $4(4.0 \%)$ \\
6 & 2 & $19(19.0 \%)$ \\
7 & 4 & $28(28.0 \%)$ \\
8 & 8 & $36(36.0 \%)$ \\
9 & 16 & $9(9.0 \%)$ \\
10 & 32 & $2(2.0 \%)$ \\
11 & 64 & $2(2.0 \%)$ \\
& Total & $100(100 \%)$ \\
\hline
\end{tabular}

Table $\mathrm{V}$ shows the sensitivity pattern of ofloxacin, ceftriaxone and azithromycin by MIC method among 40 ciprofloxacin resistant Salmonella species. All 40(100.0\%) ciprofloxacin resistant Salmonella strains were sensitive to ofloxacin and ceftriaxone. All 36 (100.0\%) ciprofloxacin intermediate sensitive strains and all 24 ciprofloxacin sensitive Salmonella strains were also sensitive to ofloxacin and ceftriaxone.

Table-V: Sensitivity pattern of ofloxacin, ceftriaxone and Azithromycin by MIC method among ciprofloxacin resistant Salmonella species $(\mathrm{n}=40)$

\begin{tabular}{lcc}
\hline Antimicrobial & \multicolumn{2}{c}{ No. of isolates } \\
Agents & Resistant & Sensitive \\
\hline Ofloxacin & $0(0.0 \%)$ & $40(100.0 \%)$ \\
Ceftriaxone & $0(0.0 \%)$ & $40(100.0 \%)$ \\
Azithromycin & No defin itiv e break points for & Salmonella isolates \\
\hline
\end{tabular}

\section{Discussion}

The present study was carried out among 100 Salmonella strains (72 Salmonella typhi and 28 Salmonella paratyphi A) to determine the MICs of four drugs and to find out the antimicrobial susceptibility pattern of Salmonella strains.

In the present study, the MIC of ciprofloxacin showed that the highest number of strains $36(36 \%)$ had MIC $2 \mathrm{~g} / \mathrm{ml}$ and 9 (9\%) showed highest MIC value $8 \mathrm{~g} / \mathrm{ml}$ indicate high level resistance to ciprofloxacin. MIC range 8 to $>32 \mathrm{~g} / \mathrm{ml}$ indicate high level resistance to ciprofloxacin ${ }^{8}$. Regarding susceptibility of the ciprofloxacin in terms of MIC value, $40 \%$ of the Salmonella isolates were resistant (MIC value 4 $\mathrm{g} / \mathrm{ml}$ ), 36\% were intermediate sensitive (MIC value 1 to 4 $\mathrm{g} / \mathrm{ml}$ ) and $24 \%$ were sensitive (MIC value $1 \mathrm{~g} / \mathrm{ml}$ ). Chowta et al. In India $18.1 \%$ Salmonella isolates were resistant to ciprofloxacin $9 \cdot$ Increase resistance to ciprofloxacin in this study might be due to widespread indiscriminate use, their oral route of administration, easy avilability and affordibility of ciprofloxacin ${ }^{10}$. In the present study intermediate susceptibility of the Salmonella isolates to ciprofloxacin was $36 \%$ (MIC $1 \mathrm{~g} / \mathrm{ml}$ ). Similar findings were reported by in India where intermediate susceptibility of the Salmonella isolates to ciprofloxacin was $39.96 \%$ (MIC $1 \mathrm{~g} / \mathrm{ml})^{11}$.

In the present study, $100 \%$ Salmonella strains were sensitive to ofloxacin $(2 \mathrm{~g} / \mathrm{ml})$. Similar findings were observed where all Salmonella strains were sensitive to oflaxacin (MICs of 0.5 to $1 \mathrm{~g} / \mathrm{ml})^{5}$. 
In India treatment failure occurred with ofloxacin therapy if infection occurred with Salmonella isolates with ofloxacin MICs $0.5 \mu \mathrm{g} / \mathrm{ml}$.The isolates among those with ofloxacin MICs of $0.075 \mathrm{~g} / \mathrm{ml}$ responded to the ofloxacin therapy ${ }^{12}$. It was also reported that most of the Salmonella isolates in their study showed ofloxacin resistance due to MICs that were $0.5 \mathrm{~g} / \mathrm{ml}$ of ofloxacin 13 .

The present study showed that, $100 \%$ ciprofloxacin resistant Salmonella strains were sensitive to ofloxacin. Another study showed that variation in result between first and second generation quinolones, 96.2\% Salmonella strains resistant for ofloxacin and $92.3 \%$ for levofloxacin . These observations indicate that fluoroquinolones should be tested individually and the ciprofloxacin not represent this group adequately 10 . It was also found that all the isolates of Salmonella were susceptible to ofloxacin while two isolates were detected to be resistant to ciprofloxacin ${ }^{14}$.

In this study $100 \%$ Salmonella strians were found sensitive to ceftriaxone with MIC $2 \mathrm{~g} / \mathrm{ml}$. Similar results were also found that, $100 \%$ Salmonella strains were ceftriaxone sensitive with MIC value 0.06 to $0.5 \mathrm{~g} / \mathrm{ml}$. In this study $100 \%$ ciprofloxacin resistent strains were sensitive to ceftriaxone 14 , 15 .

An interesting feature was observed by various other studies conducted worldwide that, there is lack of correlation between the results of disc diffusion and MIC methods 15,16 . These variations could be due to fewer Salmonella strains being tested with MIC and through random selection of the isolates. This latter hypothesis is supported by the fact that when used both method for sensitivity testing there was $90 \%$ correlation between the two methods ${ }^{15}$. MIC value of azithromycin either sensitive or resistant can not be detected because azithromycin has no definite breakpoint for Salmonella isolates ${ }^{10}$. There was as yet no data on the breakpoint of azithromycin for enteric fever which was found the MIC range to be $4-16 \mathrm{~g} / \mathrm{ml}^{17}$. Present study showed that most Salmonella strains MIC value were 4 to 8 $\mathrm{g} / \mathrm{ml}$ which is consistent to the result of another study where the MICs values of most Salmonella were $4-8 \mathrm{~g} / \mathrm{ml}^{18}$.

In this study, we have determined the minimum inhibitory concentration of azithromycin, ofloxacin and ceftriaxone. It was found that all the ciprofloxacin resistant and sensitive isolates are sensitive to these drugs. So, it can be considered that these drugs are better alternatives for treating enteric fever.

\section{Reference}

1. Cheesbrough M. Salmonella species, Part II, District laboratory practice in tropical countries. The Edinburgh Building, Cambridge, New York, 2004; 182-187.

2. Threlfall EJ and Ward LR. Decreased susceptibility to ciprofloxacin is Salmonella enterica serotype Typhi, United Kingdom. 2001; http://hinarigw.who.int/whalecomwww.cdc. govHYPERLINK "http://hinari-gw.who.int/whalecomwww.cdc. gov/whalecom()/ncidod"/HYPERLINK "http://hinari$\mathrm{g} \mathrm{w}$. wh o. i n t / w h a le co m w w w c d c . gov/whalecom()/ncidod"whalecomHYPERLINK "http://hinari-gw.who.int/whalecomwww.cdc. gov/whalecom()/ncidod"()/HYPERLINK "http://hinari$\mathrm{g} \mathrm{w}$. w h o. i n t/ w h a le c o m w w w . c d c . gov/whalecom( $) /$ ncidod"ncidod.

3. Parry CM, Hien TT, Dougan G, White NJ and Farrar JJ. (2002) Medical Progress. The New England Journal of Medicine, 2002; 347(22): 1770-1782.

4. Gaind R, Paglietti B, Murgia M, Dawar R, Uzzau S, Cappuccinelli P, Deb M, Aggarwal P and Rubino S. Molecular characterization of ciprofloxacin-resistant Salmonella enterica serovar typhi and paratyphi a causing enteric fever in India. Journal of Antimicrobial Chemotherapy, 2006; 58(6):1139-1144.

5. Parry CM, Ho VA, Phuong LT, Bay PV, Lanh MN, Tung LT, Tham NT, Wain J and Hein TT. A randomized controlled comparison of ofloxacin, azithromycin and ofloxacin-azithromycin combination for treatment of multidrug resistant and nalidixic acid resistant typhoid fever. Antimicrob Agents Chemother; 2007;51:819-825.

6. Ahmed D, Costa LT, Alam K, Nair GB and Hossain MA. Multidrug-resistant Salmonella enterica Serovar typhi isolates with high-level resistance to ciprofloxacin in Dhaka. Bangladesh. Antimicrobial Agents and Chemotherapy, 2006; 44(7):1855-1859.

7. Chinh NT, Parry CM, LY NT, HA HD, Thong MX, Diep TS, Wain J, White NJ and Farrar JJ. A randomized controlled comparison of Azithromycin and ofloxacin for treatment of multidrug-resistant of nalidixic acid-resistant enteric fever. Antimicrobial Agents and Chemotherapy; 2000; 44(7):1855-1859.

8. Rahman M, Siddique AK, Shoma S, Rashid H, Salam MA, Ahmed QS, Irais GB, Breiman RF. ICDDRB; Center for health and population research Dhaka Bangladesh, 2006; 134(2): 433-438. 
9. Chowta MN and Chowta NK. Study of clinical profile and antibiotic response in typhoid fever. Indian Journal of Medical Microbiology; 2005; 23(2):125-127.

10. Capoor MR, Nair D, Hasan AS, Aggarwal P and Gupta B. Narrowing therapeutic options in typhoid fever, India. Southeast Asian J Trop Med Public Health, 2006; 37:1170-1174.

11. Mehta G, Randhawa VS, Mohapatra NP. Intermediate susceptibility to ciprofloxacin in Salmonella Typhi strains in India. Eur J Clin Microbiol Infect Dis, 2001; 20:760761.

12. Mandal S, Mandal MD and Pal NK. Ofloxacin minimum inhibitory concentration versus disk diffusion zone diameter for Salmonella enterica serovar Typhi isolates: problems in the detection of ofloxacin resistance. Jpn $\mathrm{J}$ Infect Dis, 2003; 56:210-212.

13. Hakanen A, Kotilainen P, Jalava J, Shtonen A and Huovinen P. Detection of decreased fluoroquinolone susceptibility in Salmonellas and validation of nalidixic acid screening test. J Clin Micrbiol, 1999;37:3572-3577.
14. Kumar R, Aneja KR, Roy P, Sharma M, Gupta R, Ram S.Evaluation of minimum inhibitory concentration of quinolones and third generation cephaloporins to Salmonella Typhi isolates. Department of Microbiology, 2002; 56(1):1-8.

15. Gautam V, Gupta NK, Chaudhary U, Arora DR. Sensitivity pattern of Salmonella serotypes in northern India. Braz J Infect Dis, 2002; 6(6): 1413-8670.

16. Jevanand HR, Ragavan PUM, Gunapathi RS. Study of R-factors among multidrug resistant Salmonella Typhi. Indian J Med Microbiol, 1997; 15(1):37-9.

17. CLSI. Performance Standards for Antimicrobial Susceptibility Testing, $16^{\text {th }}$ information supplement, M100-S16. Wayne, PA: Clinical and Laboratory Standards Institute, 2006

18. Metchock B. (1990) In vitro activity of azithromycin compared with other macrolides and oral antibiotics against Salmonella Typhi. J Antimicrob Chemother; 1990; 24(suppl.A): 29-31. 